\title{
MODELADO Y SIMULACIÓN DE SISTEMAS MECATRÓNICOS
}

\section{Mauricio Castillo Effen}

\section{RESUMEN}

En este artículo se introduce el campo de la mecatrónica, su importancia y relación con los sistemas embebidos, procediendo luego a mostrar algunos retos que representa la tarea de modelar y simular sistemas mecatrónicos. Se presentan también algunos paradigmas de modelación y simulación de sistemas de éste tipo así como alternativas prácticas de cómo encarar los retos mencionados.

Palabras Clave: Software de Simulación, Mecatrónica, Sistemas de Control. 